\title{
Identifying the oldest larva of a myrmeleontiformian lacewing-a morphometric approach
}

Andrés F. Herrera-Flórez, Florian Braig, Carolin Haug, Christian Neumann, Jörg Wunderlich, Marie K. Hörnig, and Joachim T. Haug

Acta Palaeontologica Polonica 65 (2), 2020: 235-250 doi:https://doi.org/10.4202/app.00662.2019

Neuroptera is one of the smaller ingroups of Holometabola, the ingroup of Insecta characterised by "complete" metamorphosis. Neuroptera comprises about 6000 species in the modern fauna, but appears to have been more diverse in the past. While adults distantly resemble certain moths or damselflies, the larval forms of Neuroptera are mostly fierce predators with prominent venom-injecting stylets. The most well-known of these larvae are probably those of antlions. Antlions and their closer relatives (silky lacewings, split-footed lacewings, ribbon-winged lacewings, spoon-winged lacewings, and owlflies) form a distinct monophyletic ingroup of Neuroptera, Myrmeleontiformia, hence the antlion-like forms. The fossil record of antlion-like larvae dates back far into the Cretaceous; many forms are known by exceptionally wellpreserved specimens entrapped in amber. The oldest fossil record of a neuropteran larva (not an antlion-like form) comes from Lebanese amber. Interestingly, the supposedly oldest record of an antlion-like larva is preserved in rock and comes from the famous Lower Cretaceous Crato Formation. We re-evaluate this fossil based on high-resolution composite photography. Due to the non-availability of many key characters, standard procedures for identifying the specimen to a more narrow ingroup remains challenging. Therefore, we used a morphometric approach. A combination of non-metric multidimensional scaling (NMDS), parallel coordinate plots and discriminant function analysis indicates that the fossil is a representative of the group Ascalaphidae (owlflies) + Myrmeleontidae (antlions). We discuss implications of this result for the fossil record of neuropteran larvae. These include the rather derived morphology of the oldest fossil larva of Myrmeleontiformia in contrast to previous expectations. Furthermore, fossils from soil dwellers can not only be expected to be found in amber, but also as compression fossils.

Key words: Insecta, Myrmeleontidae, Ascalaphidae, compression fossil, fossil larva, Cretaceous, Crato Formation, Brazil.

Andrés F. Herrera-Flórez [andresfhf@gmail.com] and Florian Braig [ f.braig@campus.lmu.de ], Ludwig-Maximilians-Universitä t Mü nchen (LMU), Biocenter, Großhaderner Str. 2, 82152 Planegg-Martinsried, Germany. Carolin Haug [carolin.haug@palaeo-evo-devo.info] and Joachim T. Haug [joachim.haug@palaeo-evo-devo.info ], Ludwig-Maximilians-Universität München (LMU), Biocenter, 
Großhaderner Str. 2, 82152 Planegg-Martinsried, Germany and

GeoBio-Center, Ludwig-Maximilians-Universität München,

Richard-Wagner-Straße 10, 80333 München, Germany. Christian

Neumann [christian.neumann@mfn-berlin.de], Museum für Naturkunde,

Leibniz Institute for Evolution and Biodiversity Science, Invalidenstr. 43,

10115 Berlin, Germany. Jörg Wunderlich [joergwunderlich@t-online.de

], Oberer Häuselbergweg 25, 69493 Hirschberg, Germany. Marie

K. Hörnig [marie.hoernig@palaeo-evo-devo.info], University of Greifswald, Zoological Institute and Museum, Cytology and Evolutionary Biology, Soldmannstr. 23, 17489 Greifswald, Germany.

This is an open-access article distributed under the terms of the Creative Commons

Attribution License (for details please see creativecommons.org), which permits unrestricted use, distribution, and reproduction in any medium, provided the original author and source are credited.

For Full text $(1,238.8 \mathrm{kB})$ ।

Far Supplementary file $(122.9 \mathrm{kB})$ 